\title{
Durability of Syntactic Foams for Deep Offshore Insulation: Modelling of Water Uptake under Representative Ageing Conditions in Order to Predict the Evolution of Buoyancy and Thermal Conductivity
}

\author{
X. Lefebvre', V. Sauvant-Moynot ${ }^{2}$, D. Choqueuse ${ }^{3}$ and P. Chauchot ${ }^{3}$ \\ 1 Institut français du pétrole, IFP, Département Matériaux, 1-4 avenue de Bois-Préau, 92852 Rueil-Malmaison Cedex - France \\ 2 Institut français du pétrole, IFP, Département Matériaux, BP 3, 69390 Vernaison Cedex - France \\ 3 IFREMER, Centre de Brest, BP 70, 29280 Plouzané - France \\ e-mail: xavier.lefebvre@ifp.fr - valerie.sauvant@ifp.fr -dominique.choqueuse@ifremer.fr - pierre.chauchot@ifremer.fr
}

Résumé - Durabilité de mousses syntactiques utilisées en offshore profond : modélisation de la prise en eau des matériaux lors de vieillissements représentatifs et prévision de la flottabilité et de la conductivité thermique à long terme - Des vieillissements en pression (de 1 bar à 300 bar) et en température (de $4{ }^{\circ} \mathrm{C}$ à $130^{\circ} \mathrm{C}$ ) ont été réalisés sur trois sortes de mousses syntactiques plongées dans de l'eau de mer en renouvellement. Certaines propriétés fonctionnelles des matériaux ont été suivies au cours des vieillissements. En particulier, pour chaque mousse syntactique et pour tous les vieillissements, l'effet de la prise en eau sur la flottabilité et sur la conductivité thermique a été mesuré. Un modèle par éléments finis permettant de calculer la prise en eau de mousses syntactiques a ensuite été développé. Ce modèle est basé sur la description de trois mécanismes d'hydratation, chaque mécanisme étant relié à une partie de la microstructure de la mousse syntactique. L'identification des paramètres sur la base de données donne de bons résultats quelles que soient les conditions de vieillissement et la dimension des échantillons. Finalement, le modèle ainsi identifié a été utilisé pour simuler l'évolution de propriétés fonctionnelles que présenterait une structure immergée en conditions réelles pendant 20 ans. Ce calcul nous permet en outre d'estimer l'épaisseur du matériau isolant affectée par la pénétration de l'eau, valeur que nous pouvons alors utiliser au moment du design en tant qu'épaisseur sacrificielle.

\footnotetext{
Abstract - Durability of Syntactic Foams for Deep Offshore Insulation: Modelling of Water Uptake under Representative Ageing Conditions in Order to Predict the Evolution of Buoyancy and Thermal Conductivity - Three different syntactic foams were aged under various conditions of both temperature (from $4^{\circ} \mathrm{C}$ to $130^{\circ} \mathrm{C}$ ) and pressure (from 1 bar to 300 bar) in renewed sea water. Some functional properties were measured during aging. First, the link between water uptake and both buoyancy and thermal conductivity evolutions was established for each syntactic material under any ageing conditions. Then a finite element model was developed in order to compute water uptake in the materials. The model, based on the description of three hydration mechanisms, each mechanism being linked to a part of the microstructure of the foam, gives a satisfactory agreement with experimental results for all aging conditions and specimen sizes. The model was finally used to simulate the evolution of some functional properties that would experience a structure immersed in real conditions over 20 years. Furthermore, the thickness of the insulation material affected by water ingress after 20 years of aging can be estimated, and this value can be used at the time of design as a sacrificial thickness.
} 


\section{INTRODUCTION}

Since estimations of oil reserves are significant for deep water [1] and supported by current oil and gas high prices, ultra deep offshore oil exploitation (down to 3000 meters depth) presents new challenges to offshore engineering and operating companies.

Deep offshore insulation coating materials endure severe operating conditions: continuous exposure to sea water under hydrostatic pressure proportional to the depth, and large temperature gradients between the temperature of the sea (about $4^{\circ} \mathrm{C}$ ) and the temperature of steel pipe which is in contact with the effluent (up to $130^{\circ} \mathrm{C}$ ). Some problems to cope with at these depths are flow assurance and weight of offshore structures. Syntactic foams have found new fields of application in these areas: these composite materials have a low thermal conductivity as required for flow assurance, a tailored resistance to pressure due to glass microsphere fillers and they also have a low density for buoyancy benefits.

Since a long life time is generally required (up to 25 years) attention must be paid to the effect of the hydrostatic pressure, sometimes coupled with a high temperature, on the long term behaviour of the materials. In addition to comprehensive experimental studies, there is a need for models to offer prediction capability for the thermo-mechanical long-term behaviour of insulated structures [2].

In this study, a large range of syntactic foam materials was selected composed of three different matrix polymers (epoxy, polypropylene, polyurethane). Several functional properties (thermal insulation, mechanical properties, buoyancy) were tracked during ageing under conditions attempting to be representative of those in service: pressure up to $30 \mathrm{MPa}$ (300 bar) in renewed sea water, temperature up to $130^{\circ} \mathrm{C}$ for hot wet conditions. The evolution of functional properties was discussed with regards to the water uptake of each material.

The first part of this paper describes the microstructure, composition and size of the selected materials, the aging conditions under consideration and the experimental methods. The second part is dedicated to the correlation between experimental water uptake and both buoyancy and thermal conductivity evolutions for each syntactic material during ageing. Some mechanical test results are also presented and discussed. In the third part, a finite element model (FEM) is developed in order to compute water uptake in syntactic foams for all aging conditions and specimen sizes. This physical model, based on the description of the three hydration mechanisms of the three microstructural phases, is validated with regards to experimental results. In the last part, the FEM model is applied to a structure to estimate the depth of insulation material affected by the water ingress after 20 years ageing, and to compute the related evolution of functional properties of the insulation material.

\section{EXPERIMENTAL}

\subsection{Composition and Microstructure of Syntactic Foams}

The syntactic foams under study are composed of an organic matrix (polymer) and glass microspheres [3, 4]. The latter follow a Gaussian size distribution with a minimum diameter of about $10 \mu \mathrm{m}$ and a maximum diameter of about $100 \mu \mathrm{m}$. The thickness of the microsphere glass shells is around 1 to 2 microns, as shown in Figure 1, and is almost independent of the sphere diameter $[5,6]$. Syntactic foam microstructure depends on both the volume ratio and the polydispersity of glass microspheres. The volume ratio of glass microspheres in a syntactic foam usually varies from $40 \%$ to $60 \%$ to achieve given thermal and mechanical properties and is a function of the nature of the matrix and related processing.

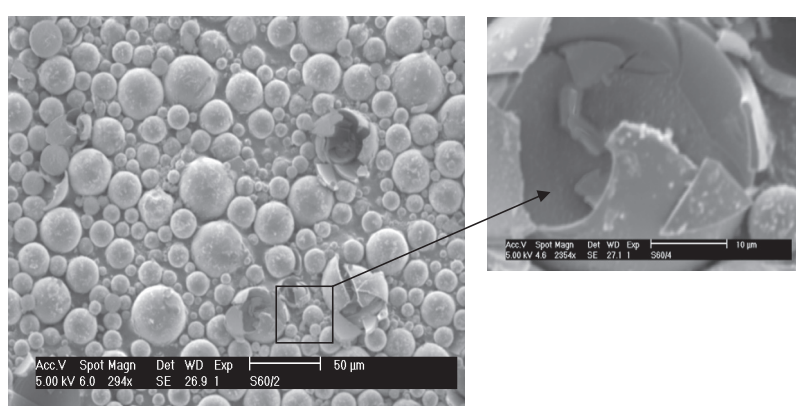

Figure 1

Scanning electron micrograph - Detail of a broken glass microsphere.

Four materials were selected in this study according to their density, thermal conductivity, glass transition temperature, and mechanical properties (crush pressure, compressive strength, etc.). They are supposed to sustain deep water service conditions up to $3000 \mathrm{~m}$. Compositions of the 3 syntactic foams reported in Table 1 are mostly differing by the nature of the matrix: epoxy resin (material A), polypropylene resin (material B) and polyurethane resin (material C). This choice was made to characterize various water uptake behaviours and to cover a wide range of potential applications. Glass microspheres manufactured by the company $3 M^{\circledast}$ were all of the same volumic mass, but the high strength grade with a reduced diameter distribution towards larger and smaller diameters provides a higher mechanical resistance to hydrostatic pressure [3]. In addition to these three syntactic 
foams, a solid rubber material (material D) was also selected due to its promising initial thermal and mechanical properties.

TABLE 1

Composition of the 4 selected materials (3 syntactic foams and a rubber)

\begin{tabular}{c|c|c}
\hline Material & Matrix nature & Glass microspheres \\
\hline A & Epoxy & S 38 High strength $\left(3 M^{\circledast}\right)$ \\
\hline B & Polypropylene & S 38 High strength $\left(3 M^{\circledast}\right)$ \\
\hline C & Polyurethane & S 38 $\left(3 M^{\circledast}\right)$ \\
\hline D & Rubber & None \\
\hline
\end{tabular}

\subsection{Aging Conditions and Program}

Aging was performed in pressure vessels with renewed sea water. Thirteen conditions with different pressure and temperature were defined, with pressure ranging from 1 bar to $300 \mathrm{bar}$ and temperature ranging from $4^{\circ} \mathrm{C}$ to $130^{\circ} \mathrm{C}$. In this paper we will focus on two different pressures and temperatures: $P_{1}, P_{2}, T_{1}$ and $T_{2}$ with $P_{1}<P_{2}$ and $T_{1}<T_{2}$.

Several geometries of samples were used:

- homothetic cube-shaped specimens dedicated to the water uptake study (four sizes with $10 \mathrm{~mm}(S / V=0.6), 20 \mathrm{~mm}$ $(S / V=0.3), 50 \mathrm{~mm}(S / V=0.12)$ and $100 \mathrm{~mm}(S / V=0.06)$ edge sizes). The interest of testing samples of different Surface to Volume ratios $(S / V)$ has been reported in details in [7]. To a first approximation, the weight increase of these specimens was supposed to represent the water uptake. This is correct as long as there is no degradation of the material inducing superimposed mass loss;

- disc samples to follow material thermal properties during aging (thermal conductivity);

- parallelepipedic samples to study material mechanical properties during aging. Only Dynamic Mechanical Analysis results are reported in this paper.

The maximum duration of aging was $10000 \mathrm{~h}$ and several sampling periods were used, depending on analysis.

\subsection{Testing Methods}

The water uptake of aged samples was calculated considering the mass of the sample at the initial state $\left(m_{t=0}\right)$ and the final mass at a given ageing time $\left(m_{t}\right)$ using Equation (1):

$$
\text { Water Uptake }(\%)=\left(\left(m_{t}-m_{t=0}\right) / m_{t=0}\right) \times 100
$$

Thermal properties were characterized at the initial state and during ageing by measuring the thermal conductivity of two disc shaped samples (diameter $=51 \mathrm{~mm}$, thickness $=$ $5 \mathrm{~mm}$ ) at $40^{\circ} \mathrm{C}$ to limit the water evaporation during the test. An heat flow meter instrument C-Matic from Holometrix was chosen for the thermal conductivity measurements during the ageing test program in compliance with ASTM C518 or ISO 8301. Indeed, this allows small wet samples to be tested and gives reproducible $( \pm 2 \%)$ and stable results. Extensive experimental details are provided in [8].

Dynamic Mechanical Analysis (DMA) was performed at the initial state and during ageing on two samples to test the physical properties of materials subjected to a mechanical loading in the elastic domain. The instrument used was a DMA 2980 of TA Instruments, where the specimen $(40 \mathrm{~mm}$ $\times 7 \mathrm{~mm} \times 3 \mathrm{~mm}$ ) was mounted on a clamp (single-cantilever bending geometry) and then subjected to a sinusoidal displacement $(+/-32 \mu \mathrm{m})$ at a frequency of $1 \mathrm{~Hz}$ while undergoing a ramp of temperature from $-150^{\circ} \mathrm{C}$ to $120^{\circ} \mathrm{C}, 200^{\circ} \mathrm{C}$ or $250^{\circ} \mathrm{C}$ depending on the material. DMTA allows the determination of the apparent elastic modulus or storage modulus, i.e. the stiffness of the material, and of the damping coefficient (Tan $\delta=G^{\prime} / G^{\prime}$ ) as a function of temperature. The latter is related to the phase shift appearing between the loading (the sinusoidal displacement) and the response of the material (in terms of stress), reflecting the viscoelastic properties of polymers.

\section{WATER UPTAKE AND FUNCTIONAL PROPERTY EVOLUTION}

\subsection{Water Uptake Mechanisms and Models}

\subsubsection{Mechanism of Water Uptake in Polymers - Fick Law}

The matrix materials of the syntactic foams under study are polymers (thermoplastic and thermoset). Diffusion in polymers is commonly described by the Fickian diffusion model [9-11]. With $D$, the diffusion coefficient, and $c$, the concentration of the diffusing species, the Fickian law is written as follows:

$$
\frac{\partial c}{\partial t}+\nabla(-D \cdot \nabla c)=0
$$

When Fick is law satisfactorily describes one material water uptake, the water uptake curves of homothetic specimens plotted versus (Surface/Volume)*Time ${ }^{(1 / 2)}$ merge at the very beginning (linear part) and at the saturation. Saturation is not always visible on curves because the time to reach the saturation level can be very long. It is worth noting that adsorption of water at the surface can be visible at the beginning of the curves for small samples, when the surface of the sample becomes dominant with respect to its volume (see Fig. 2).

In terms of temperature dependence, the diffusion coefficient $D$ usually follows an Arrhenius law [10,11]:

$$
D=D_{0} \cdot e^{\frac{-E_{a}}{R T}}
$$




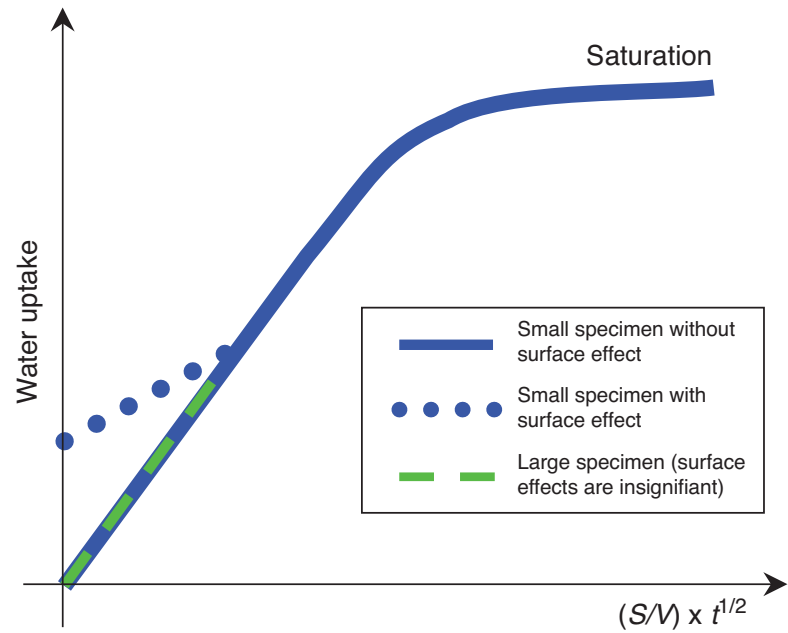

Figure 2

Schematic representation of water uptake curves in a material exhibiting a Fickian behaviour.

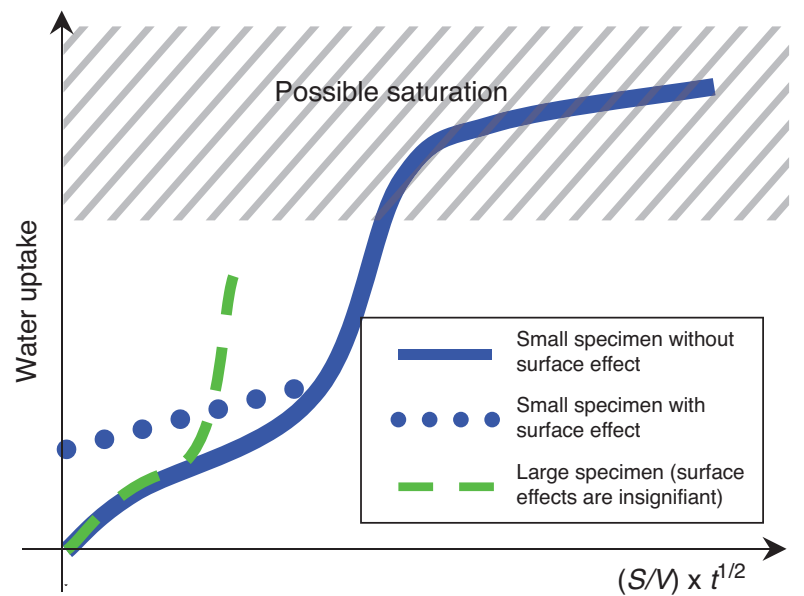

Figure 3

Sketch of water uptake curves for syntactic materials. with $D_{0}$ the pre-exponential factor and $E_{a}$ the activation energy, both being characteristics of the pair: diffusive species - material.

\subsubsection{Mechanisms of Water Uptake in Syntactic Foams}

According to previous studies [7, 8, 12, 13], the long term water uptake of syntactic foam immersed in sea or tap water cannot be modelled by a Fickian law when the temperature is above $40^{\circ} \mathrm{C}$. Since water uptake in syntactic foams is linked to the hydration of all components (polymer, glass, interfaces and void), there is a wide range of water uptake curves for these materials. In general, if the water uptake curves are presented for homothetic specimens in the same coordinates as for a Fickian material, curves can merge over small domains only (see Fig. 3). In the case of syntactic foams, the saturation is rarely visible but corresponds to more than $50 \%$ of the initial weight of a sample when all spheres are filled with water!

The presence of water in a syntactic foam specimen is due to the diffusion of water from the surface to the core of the specimen. In addition to plasticisation, the presence of water in the microstructure can induce several chemical and physical modifications (hydrolysis, lixiviation, swelling, etc.). In this paper, we will not focus on the description of these mechanisms but an overview can be found in [12, 13]. Other studies also focused on the effect of hydrostatic pressure on water ingress, specially in syntactic foams $[14,15]$.

Based on the existence of these mechanisms, the water ingress in syntactic materials subjected to irreversible ageing can be modelled as the result of three mechanisms related to each material component:

- matrix hydration;

- glass hydration: matrix/microsphere interface hydration and glass corrosion;

- microsphere cavity filling with water.

These mechanisms are proposed to be the main physicochemical sources of mass gain measured on the syntactic specimens when exposed to water, in addition to the sample surface hydration (proportional to the surface/volume ratio). Each contributes to the global amount of water uptake and the preponderance of each mechanism depends on ageing conditions (defined by external parameters such as temperature, pressure and water composition) but also on the durability of each component.

\subsection{Water Uptake Data}

\subsubsection{Water Uptake of the Three Syntactic Foams}

Water uptake curves versus the reduced square root of time for the four Surface/Volume ratios are represented in Figure 4 for the three selected syntactic foams aged under two conditions of temperature-pressure. These results clearly illustrate the wide range of water uptake behaviour of syntactic foams during hydrothermal aging.

Evolution of water uptake during aging at (T1, P1):

- The water uptake rate of material $A$ is very low and constant whatever the geometry. Initial water uptake 

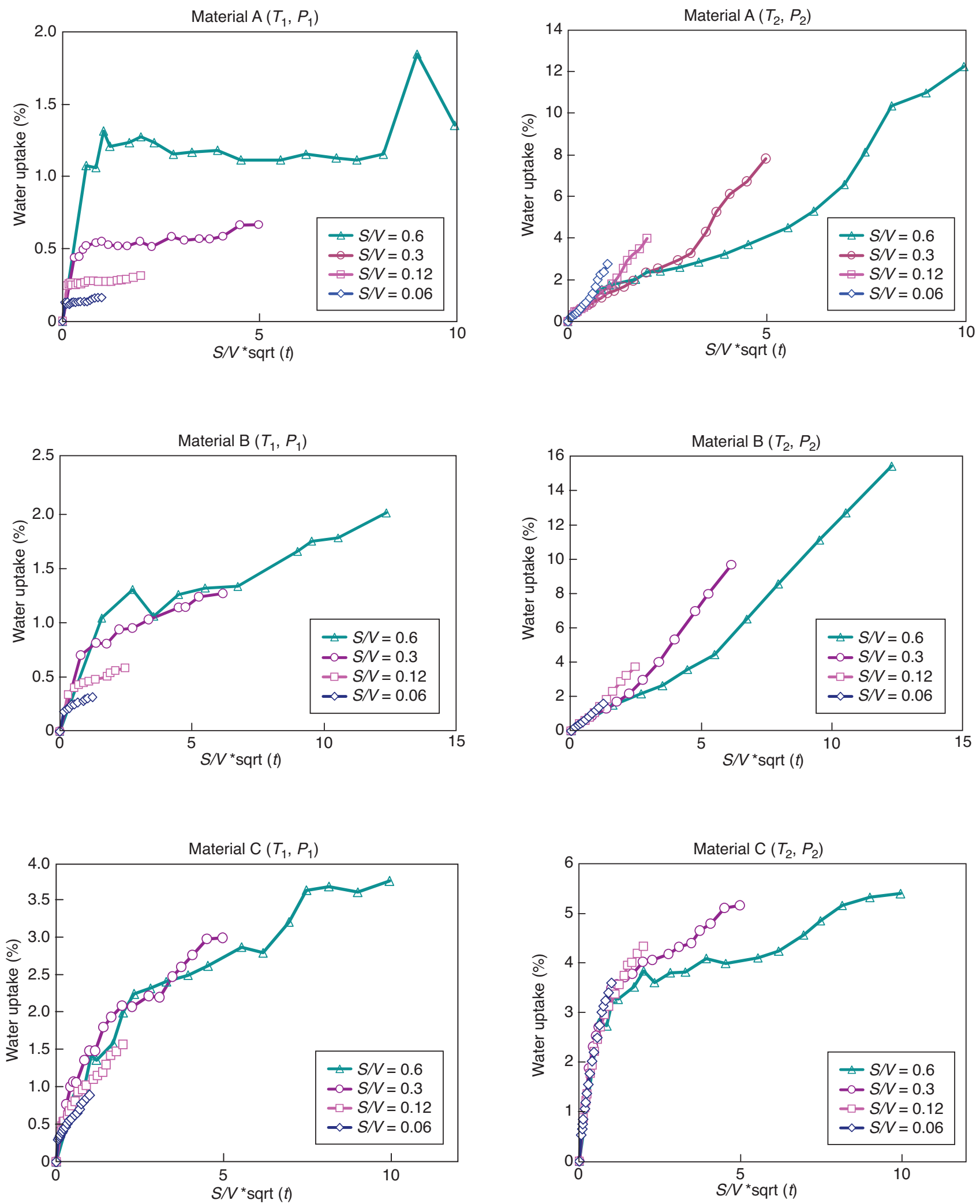

Figure 4

Water uptake curves of the three selected syntactic foams during aging at $\left(T_{1}, P_{1}\right)$ and at $\left(T_{2}, P_{2}\right)$. Geometries are characterized by $S / V$ ratios. 

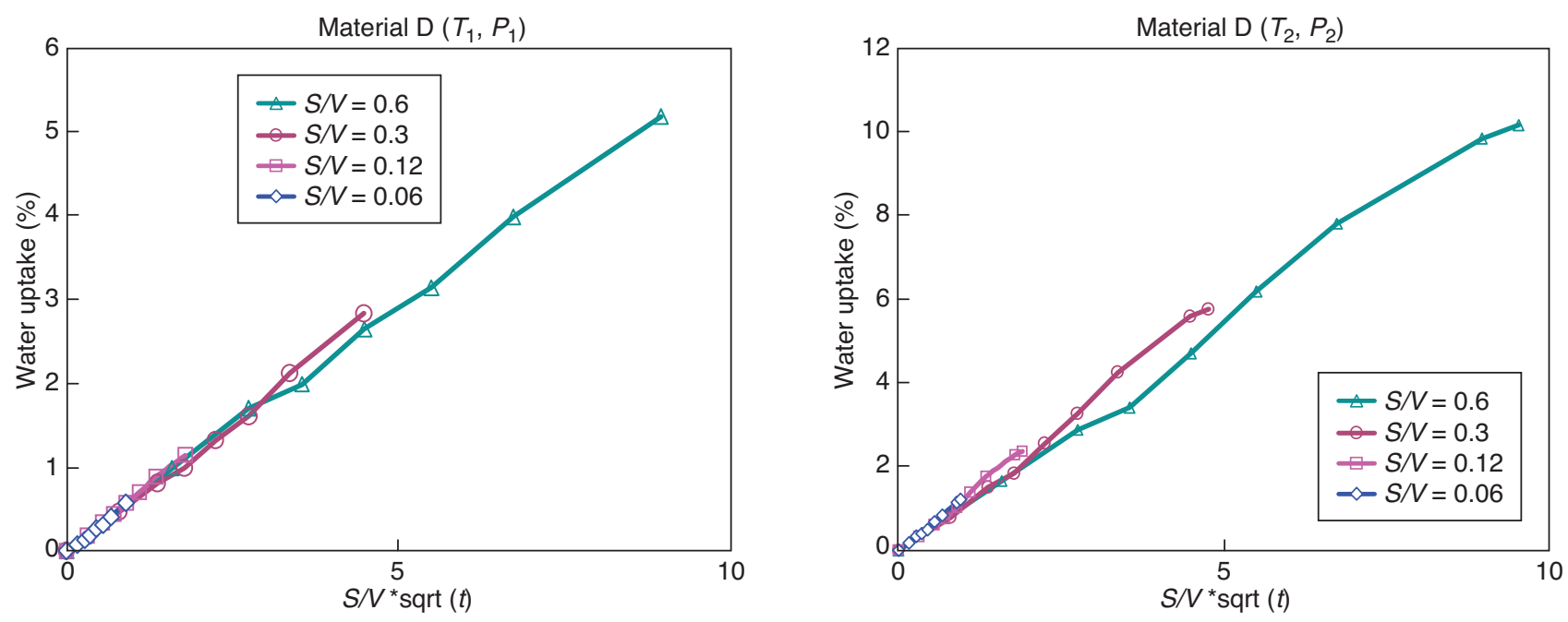

Figure 5

Water uptake curves of the rubber (material D) during aging at $\left(T_{1}, P_{1}\right)$ and at $\left(T_{2}, P_{2}\right)$. Geometries are characterized by $S / V$ ratios.

values are proportional to surface/volume ratios. This means that this water uptake is mainly due to surface effects.

- The water uptake rate of material $B$ is constant and initial water uptake values are proportional to surface/volume ratios, revealing surface effects. It is not clear yet if the curves merge or not.

- The water uptake in material $C$ seems to be Fickian at $\left(T_{1}, P_{1}\right)$ because all curves merge. Initial values are not significantly affected by surface effects.

Evolution of water uptake during aging at (T2, P2):

- After a pseudo saturation level at $2 \%$, the water uptake curves of material $A$ and $B$ increase promptly again and do not merge. This is a non Fickian behaviour.

- After a pseudo Fickian saturation level at 4\%, the water uptake curves of material $C$ also increase again, but less rapidly than for other materials, exhibiting a non-Fickian behaviour (curves diverge beyond $4 \%$ of water uptake).

These results illustrate that both temperature and pressure can have a strong effect on the water uptake behaviour of a given material. For instance, a material having a Fickian behaviour at $T_{1}$ and/or $P_{1}$ can completely deviate from the Fickian behaviour at $T_{2}$ and/or $P_{2}$.

\subsubsection{Water Uptake of the Rubber Material}

Water uptake curves for the rubber material are plotted in Figure 5 versus the reduced square root of time for the four Surface/Volume ratios. All curves clearly merge, suggesting that water diffusion in this material follows a Fickian mechanism. The water uptake in the small specimen $(S / V=0.6)$ seems to reach a saturation level after ageing for $10000 \mathrm{~h}$ at $\left(T_{2}, P_{2}\right)$. Thus modelling will be performed using a Fickian law with the saturation level at $25 \%$.

\subsection{Consequences of Water Uptake for Some Functional Properties}

Some functional properties have been measured during aging. In this paper we are focusing on buoyancy, thermal conductivity evolution and mechanical properties as given by DMA.

\subsubsection{Buoyancy Evolution during Aging}

Since no significant swelling was observed on specimens, the buoyancy evolution is considered as directly linked to the water uptake of the specimen. So, buoyancy evolution curves directly follow water uptake curves (see Fig. 4, 5) corrected for the relative densities of both water and material.

Under these conditions, modelling of water uptake will directly give the buoyancy evolution of a specimen.

\subsubsection{Thermal Conductivity Evolution of Syntactic Foams during Aging}

The evolution of thermal conductivity $(\lambda)$ measured at $40^{\circ} \mathrm{C}$ on wet aged samples is discussed with respect to their water uptake. 
The following analysis is performed to compare the experimental variation of $\lambda$ to the "theoretical" one, where the water content (in volume) within the material directly accounts for the thermal conductivity increase [8].

The experimental variation of $\lambda$ is calculated considering the value after ageing and the initial one:

$$
\Delta \lambda_{\text {experimental }}=\lambda_{t}-\lambda_{t=0}
$$

The theoretical variation of $\lambda$ is obtained by using a mixture law based on the following hypotheses:

$$
\Delta \lambda_{\text {theoretical }}=v \times \lambda_{\text {water }}
$$

with $\lambda_{\text {water }}\left(40^{\circ} \mathrm{C}\right)=0.61 \mathrm{~W} / \mathrm{m} . \mathrm{K}$ and $v$ the volume fraction of water in the sample:

$$
v=\left(m_{\text {water }} / \rho_{\text {water }}\right) / V_{t}
$$

with $m_{\text {water }}$ the mass of water absorbed, $V_{t}$ the volume of the sample measured after a given ageing and $\rho_{\text {water }}$ the density of water $\left(\rho_{\text {water }}=1 \mathrm{~kg} \cdot \mathrm{m}^{-3}\right)$.

Results for experimental and theoretical variations of thermal conductivity after aging are presented in Figure 6. Four aging conditions at 300 bar are represented for each material. The $y=x$ line is plotted on the graph to visualize if the mixture law based on water uptake and thermal conductivity of water at $40^{\circ} \mathrm{C}$ accounts for the evolution of the thermal conductivity during aging.

For a given material, one can observe that the thermal conductivity increases almost linearly according to a volume mixture law whatever the ageing condition ( $T$ ranging from

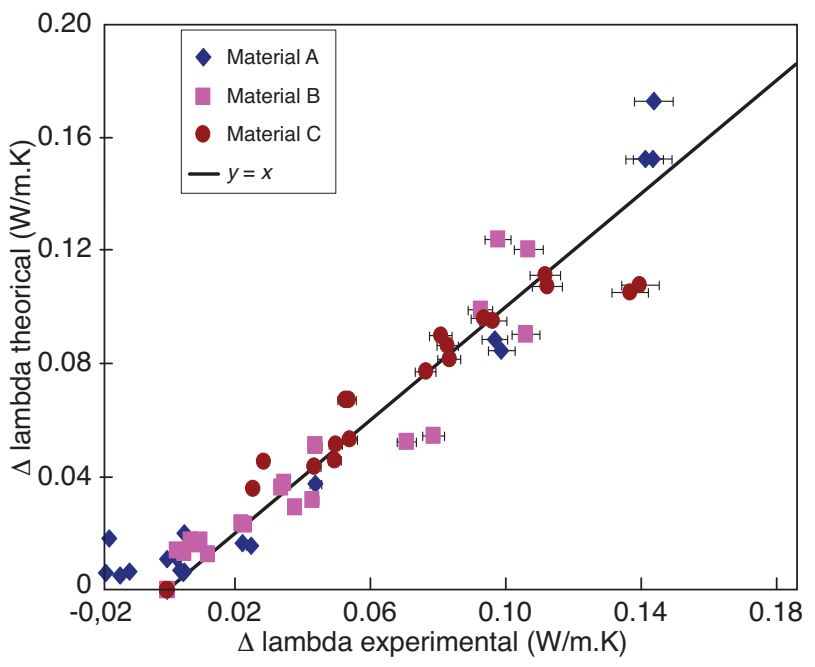

Figure 6

Thermal conductivity evolution of the three syntactic foams during aging ( 4 aging conditions at 300 bar). Good correlation between theoretical and experimental conductivity. $4^{\circ} \mathrm{C}$ to $130^{\circ} \mathrm{C}$ ). This common mixture law confirms that those materials behave in the same manner when they are immersed in seawater for a long time. This is not surprising since microspheres used in these foams are of the same composition and geometry. Thus they would undergo similar damage due to water entry, leading to the aforementioned increase of their thermal conductivity.

In conclusion, all water content (in vol.) accounts for the evolution of thermal properties, in agreement with previous studies [8]. As a result, the modelling of the water uptake during aging will allow thermal conductivity evolutions to be computed.

\subsubsection{Mechanical Property Evolution for Syntactic Foams during Aging}

The evolution of the temperature related to the maximum damping factor of wet aged syntactic foam samples (this peak is considered to define the glass transition temperature, $T g$ ) is presented in Table 2 and the evolution of storage moduli measured at $20^{\circ} \mathrm{C}$ by DMTA is presented in Table 3. Results after ageing are discussed in comparison to reference samples characterized as received. Note that as received materials have not been pressurised before: they are free of any ageing and free of any pressure damage.

TABLE 2

Temperature (in ${ }^{\circ} \mathrm{C}$ ) of the maximum damping factor $\tan \delta$ before/after ageing in seawater at $40^{\circ} \mathrm{C} 300$ bar

\begin{tabular}{c|c|c|c}
\hline & Material A & Material B & Material C \\
\hline As received & 157 & -36 & 30 \\
\hline 2000 h ageing & 155 & -34 & 18 \\
\hline 10000 h ageing & 163 & -30 & 23 \\
\hline
\end{tabular}

TABLE 3

Storage moduli (in $\mathrm{MPa}$ ) measured at $20^{\circ} \mathrm{C}$ before/after ageing in seawater at $40^{\circ} \mathrm{C} 300 \mathrm{bar}$

\begin{tabular}{c|c|c|c}
\hline & Material A & Material B & Material C \\
\hline As received & 3035 & 920 & 195 \\
\hline $2000 \mathrm{~h}$ ageing & 2845 & 825 & 65 \\
\hline $10000 \mathrm{~h}$ ageing & 2680 & 585 & 95 \\
\hline
\end{tabular}

All syntactic materials exhibit a decreasing storage modulus upon ageing due to the matrix plasticisation by water. For syntactic foam A, $T g$ values are almost stable after short/long term ageing due to the water desorption occurring in the samples during measurements. In that case, the relative stability of $T g$ values indicates that the epoxy matrix is mostly affected by reversible plasticisation upon ageing. For the syntactic foam B, the almost unchanged $T g$ values are explained by the low solubility of water into a polypropylene 


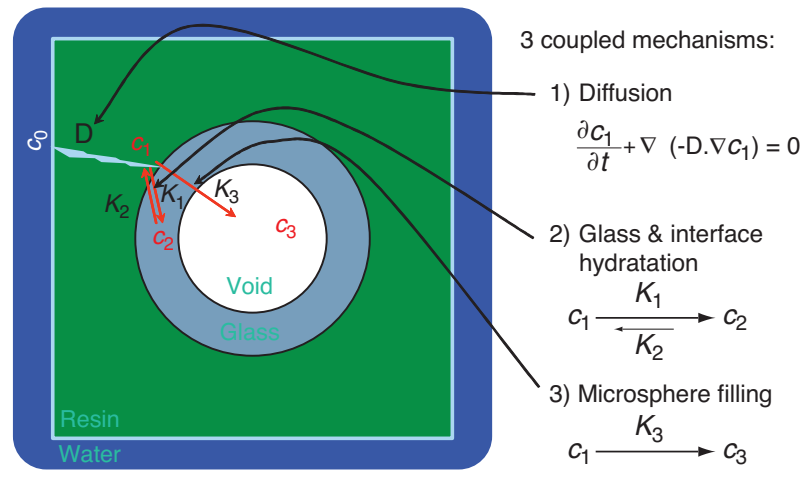

Figure 7

Coupled physical mechanisms of water uptake described by the WU model.

matrix. On the contrary, the plasticisation effect due to water ingress into the syntactic foam $\mathrm{C}$ with a polyurethane matrix is more visible on the wet $T g$ values (note that no desorption is expected during the ramp in such a temperature range).

In conclusion, DMTA measurements mainly account for the matrix behaviour and do not seem to reflect the water uptake related to damaged microspheres.

\section{WATER UPTAKE MODELING OF SYNTACTIC FOAM}

\subsection{Description of the Water Uptake Model}

A finite element model of the kinetics of the water absorption in syntactic foams was developed in Comsol Multiphysics ${ }^{\circledast}$ and Matlab ${ }^{\circledast}$. It will be referred in this paper as the water uptake model or WU model. Based on the physico-chemical mechanisms pointed out in the first part of this paper, it consists of the coupling of three mechanisms of water uptake in an homogeneous material under the assumptions at the microscopic scale given in Figure 7.

In addition to water uptake related to skin hydration (proportional to the surface), the system of partial differential equations combines the elementary mechanisms detailed in Equations (7-9).

- 1st mechanism - Matrix hydration by a Fickian diffusion law:

$$
\frac{\partial c_{1}}{\partial t}+\nabla\left(-D \cdot \nabla c_{1}\right)=0
$$

- variable: water concentration in the matrix $C_{1}$;

- kinetics coefficient: $D$, diffusion coefficient of the Fick's law;

- thermodynamic coefficient: $C_{1 \max }$, corresponding to the water quantity that can be absorbed by the pure matrix at equilibrium $\left(C_{1 \max }\right.$ stands for the solubility of water in the matrix).
- 2nd mechanism - Matrix/glass interfaces \& glass hydration governed by an equilibrium reaction between the water in the matrix and the water in the interface and glass:

$$
\frac{\partial c_{2}}{\partial t}=K_{1} c_{1}-K_{2} c_{2}
$$

- variable: water concentration in the interface and glass $\mathrm{C}_{2}$;

- kinetics coefficient: $K_{1}$, governs glass \& interface hydratation kinetics, i.e. $C_{2}$ creation kinetics;

- thermodynamic coefficient: $R=K_{1} / K_{2}$ is the thermodynamic equilibrium constant $\left(R=C_{2} / C_{1}\right.$ at balance). $C_{2 \max }=R \times C_{1 \max }$ characterizes the maximum concentration of water in the glass \& interfaces at equilibrium.

- 3rd mechanism - filling of microsphere cavities governed by a total reaction from water sorbed in the matrix:

$$
\frac{\partial c_{3}}{\partial t}=K_{3} c_{1}
$$

- variable: water concentration in the microsphere cavities $C_{3}$;

- kinetics coefficient: $K_{3}$ governs the water filling microsphere cavities, i.e. $C_{3}$ creation kinetics;

- thermodynamic coefficient: $C_{3 \max }$ corresponding to the maximum concentration of water inside the internal volume of microspheres.

The coupling of these three mechanisms results in the modelling of water uptake in all points of the syntactic foam specimen:

$$
C_{\text {water }}=C_{1}+C_{2}+C_{3}
$$

It is worth noting that the global WU model also takes into account the skin hydration as a preliminary effect.

The validation of the model is achieved by fitting the experimental water uptake curves obtained for different size cubes under given ageing conditions using a unique set of coefficients. Moreover, a practical interest of modelling using a finite element code is to implement results on various geometries very easily. This will also be true for the up-scaling of the model on industrial structures whatever the geometry (see Sect.4).

\subsection{Water Uptake Modelling of Syntactic Foam during Aging}

\subsubsection{Comparison of WU Model and Experimental Results}

Water uptake curves were fitted with the WU model and the comparison of experimental and numerical curves, for all syntactic materials, are provided in Figure 8 for two ageing conditions. As mentioned previously, the coefficients of the 

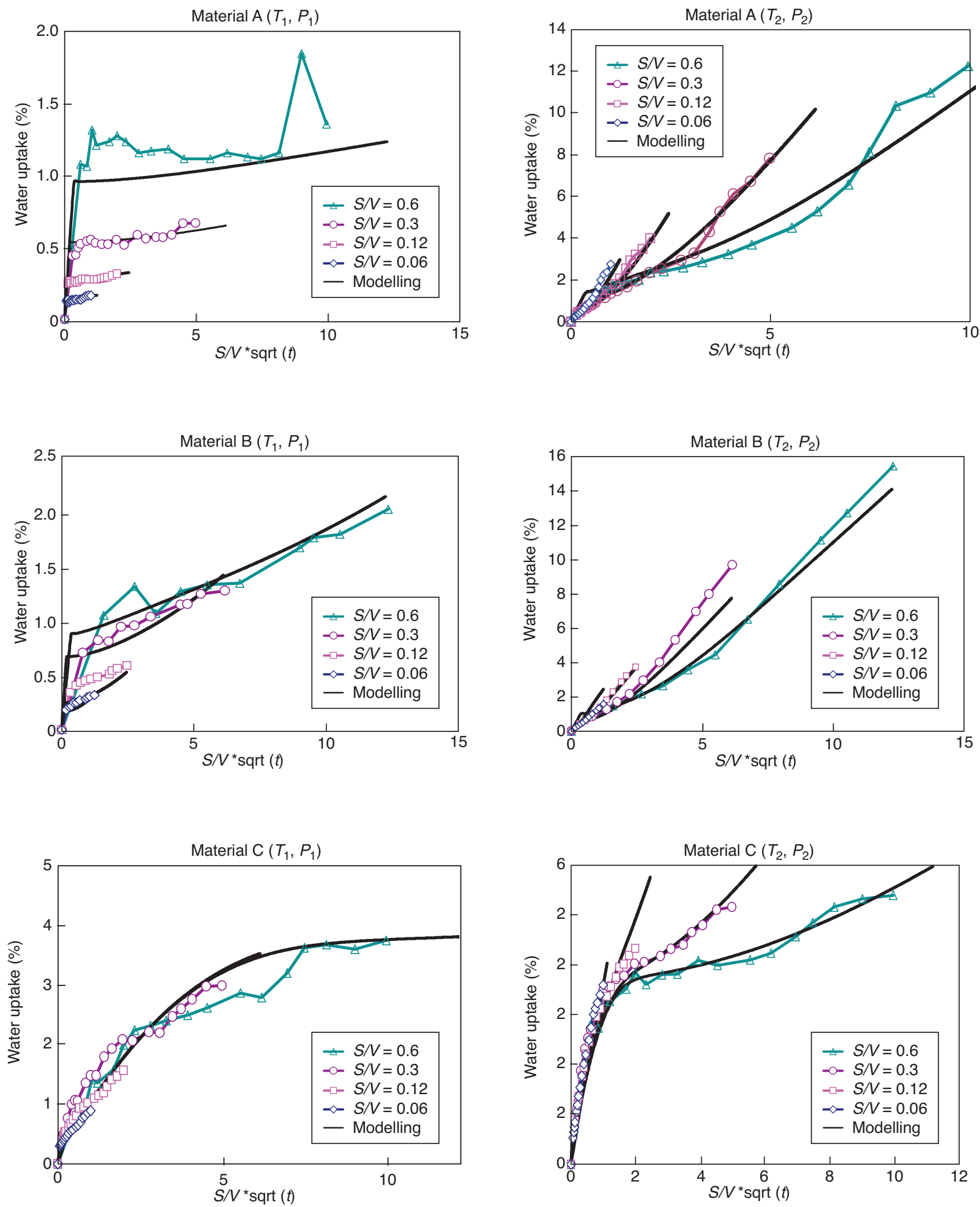

Figure 8

Experimental and numerical water uptake curves for the three syntactic foams, 4 geometries and 2 ageing conditions under study. 
model were taken as constant for all geometries. Figure 8 shows that each specific behaviour is correctly taken into account:

- Materials $A$ and $B$ : The water uptake rates functions of specimen size with respect to a Fickian law, are well fitted; skin effects are also properly taken into account;

- Material C: The pseudo-Fickian saturation level and behaviour until $4 \%$ of water uptake is well reproduced. Above this level, the water uptake acceleration, function of specimen size with respect to a Fickian law, is well transcribed. This material does not exhibit any skin effect.

The solubility and diffusion coefficients used in the first mechanism of the WU model (Fick's law) were defined according to the well-known behaviour in water of pure matrix polymers. For others mechanisms, it was clear that each coefficient could be linked to some material properties. For instance, the quality of glass-matrix interfaces affects the concentration of water at the interface ( $R$ parameter), the chemical nature of glass governs the hydration kinetic factor $\left(K_{1}\right)$, the mechanical properties of glass microspheres ( $\mathrm{S} 38$ or S38 HS) influence the microsphere filling kinetics $\left(K_{3}\right)$. The temperature dependence and pressure dependence of the model coefficients are discussed in the following paragraphs.

As a conclusion, experimental water uptake curves are well reproduced whatever the geometry and ageing conditions for three different syntactic foam materials. This is a validation of the WU model. As a consequence, functional properties such as buoyancy and thermal conductivity could be simulated on the basis of the WU model using mixture laws as explained in Section 2.

\subsubsection{Coefficient Dependence on Temperature}

For each syntactic foam material, thermodynamics coefficients of the model $\left(C_{1 \max }, C_{2 \max }, C_{3 \max }\right)$ are almost independent of the temperature whereas kinetics parameters of the model $(D$, $K_{1}, K_{3}$ ) follow an Arrhenius law between $4^{\circ} \mathrm{C}$ and $130^{\circ} \mathrm{C}$, as described in Equation (3). This means that mechanisms described by these coefficients are thermally activated as expected for kinetics coefficients. For instance, Arrhenius laws are represented in Figure 9 for material A.

Calculated activation energies vary from $45 \mathrm{KJ} / \mathrm{mol}$ to $80 \mathrm{KJ} / \mathrm{mol}$ and all correlation coefficients are superior to 0.99 . The opportunity to correctly describe model coefficient dependence on temperature with suitable Arrhenius laws consolidates the relevance of the WU model.

\subsubsection{Coefficient Dependence on Pressure}

The WU model description shows that there is no equation related to the mechanical resistance of glass microspheres to account for the possible crush of glass microspheres due to the effect of hydrostatic pressure. In fact, coefficients of the model may change as functions of the hydrostatic pressure; thus pressure effects are indirectly considered. This is

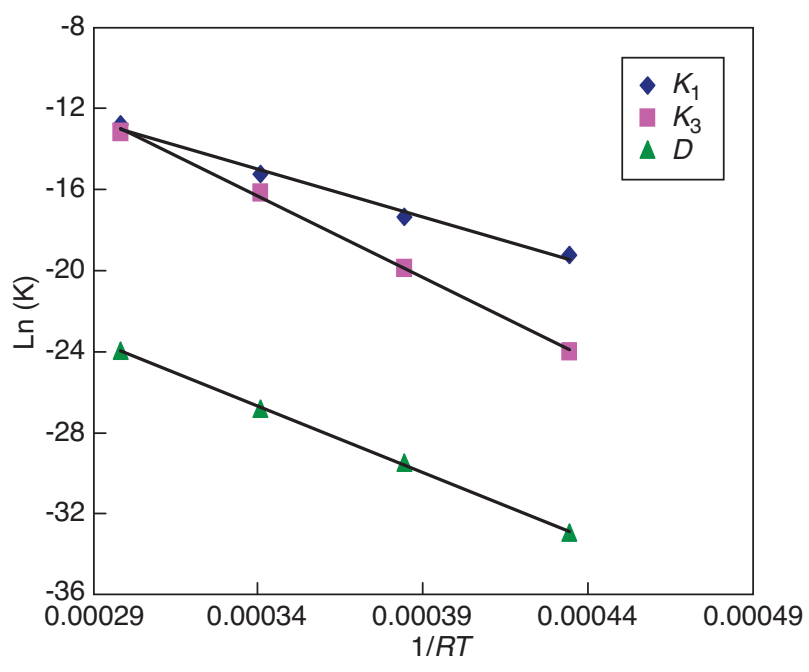

Figure 9

Arrhenius laws followed by $K_{1}, K_{3}$ and D between $4^{\circ} \mathrm{C}$ and $130^{\circ} \mathrm{C}$ (material A).

particularly the case of $C_{3 \max }$ in soft matrix foams (materials $\mathrm{B}$ and $\mathrm{C}$ ). Indeed, the quantity of water that can enter the microspheres is strongly dependent on the hydrostatic pressure and matrix rigidity. Under high hydrostatic pressure, microspheres are prone to collapse in soft foams. Actually, when a glass microsphere collapses in a soft matrix, the resulting open cell will shrink allowing less water to penetrate into the cavity. This phenomenon is reinforced with increasing pressure. Dependence of rigid matrix foam coefficients (material A) on pressure are much weaker, which underlines the good resistance of the rigid foam microstructure during pressure increase and the long term aging.

\section{MODELLING OF A REPRESENTATIVE SYNTACTIC FOAM VOLUME UNDER SERVICE CONDITIONS}

In this part, the objective is to use the WU model to simulate the water ingress into a scaled-up syntactic foam specimen, such as typical insulation half shells.

\subsection{Geometry and Modelling Configuration of the Representative Volume}

To a first approximation, the syntactic foam half shell was considered as a parallelepipedic syntactic foam block 2 meters long by 50 centimeters width and 30 centimeters thickness. In order to simulate service conditions, the block was completely immersed in water. One face of this block was maintained at $80^{\circ} \mathrm{C}$ (temperature near the production pipe), the other face was placed at sea temperature, taken as 
$4^{\circ} \mathrm{C}$. By symmetry, the meshed volume was 1 meter long by 25 centimeters width by 30 centimeters thick (see Fig. 10).

Coefficients of material A were used since this syntactic foam with a rigid matrix exhibits the best behaviour with respect to aging and pressure, namely low water uptake and volume variation at 300 bar.

The water uptake of this block was modelled at 1 bar, corresponding to the case when the block is placed near the sea surface, and at $300 \mathrm{bar}$, corresponding to the case when the block is placed at 3000 meters depth.

\subsection{Modelling of the Water Uptake of a Syntactic Foam Block}

Two maps of simulated water ingress after 20 years of aging in both configurations, respectively 1 bar and 300 bar, are presented in Figure 11. The water ingress is mainly limited near the $80^{\circ} \mathrm{C}$ face and is logically greater at 300 bar than at 1 bar.

The water uptake profiles, in a cross-section after 20 years of ageing, are plotted in Figure 12. Modelling results are represented using several water uptake models:

- the WU model at 1 bar;

- the WU model at 300 bar;

- the Fickian model assuming that the diffusion coefficient is the same as in WU model and water maximum concentration is the sum of all water amounts that can be stored in the material, i.e. about $60 \%$ by weight.

It may be noted that water ingress predicted by the WU model is limited to the first 5 centimeters whatever the temperature and pressure conditions. This is an important

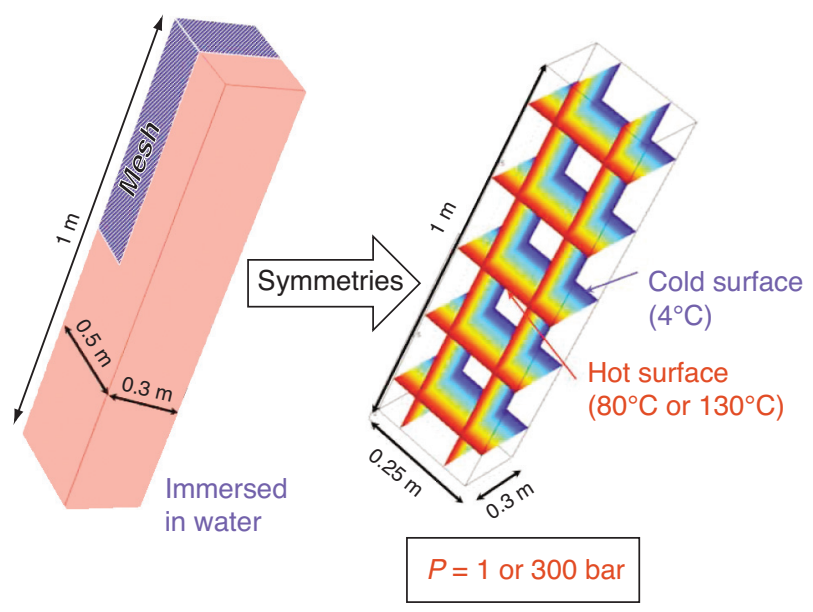

Figure 10

Block of syntactic foam immersed in water - details of the meshed geometry. result, which means that a sacrificial thickness of 10 centimeters $(5 \mathrm{~cm}$ on each face) should be anticipated during the design of the structure.

Prediction by the Fick law is much more pessimist, mainly because water solubility is taken to be equal to $60 \%$. If we only consider water solubility of the matrix (2\%), prediction would have been more optimistic, but surely not realistic! The sacrificial thickness to be taken into account using the traditional Fick law is two times greater than the one estimated by the WU model. This discrepancy between the traditional conservative approach and the present modelling is huge in terms of sacrificial insulation volume. This result could directly impact the design of future insulation structures.

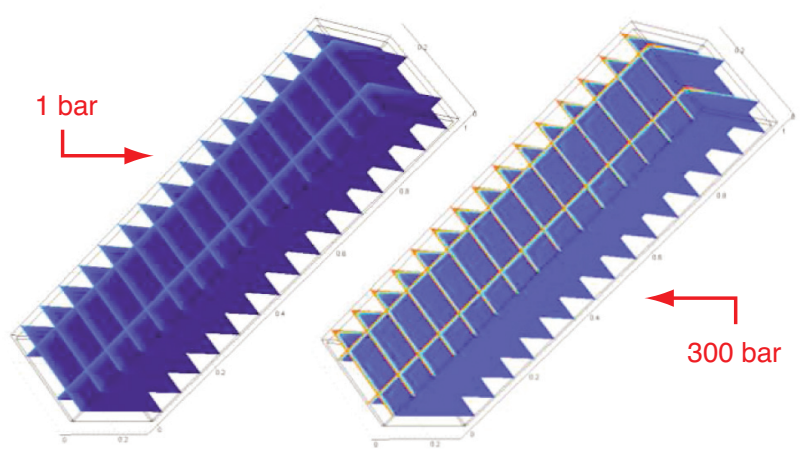

Figure 11

Maps of water ingress after 20 years of aging at 1 bar and at 300 bar.

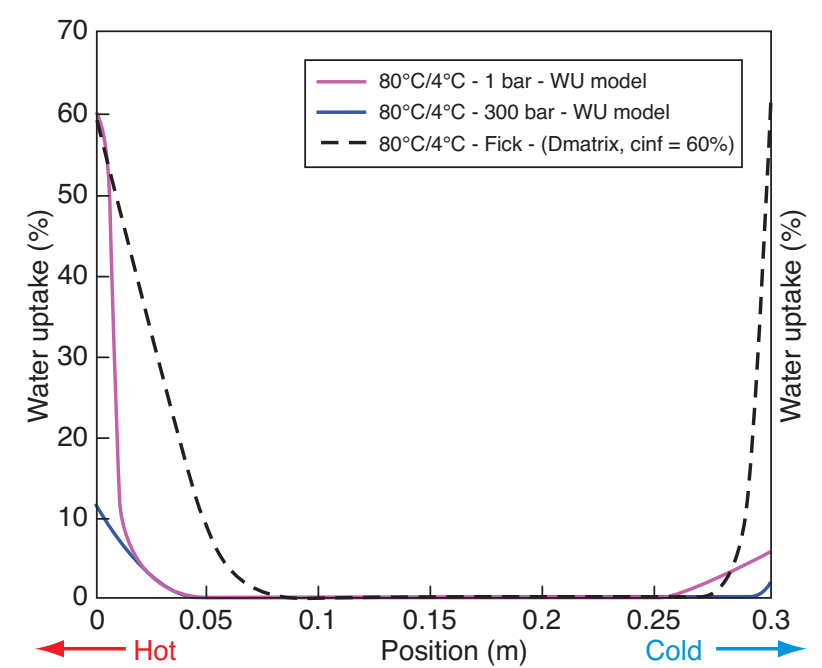

Figure 12

Water uptake is simulated in a cross-section after 20 years of aging using different models. 


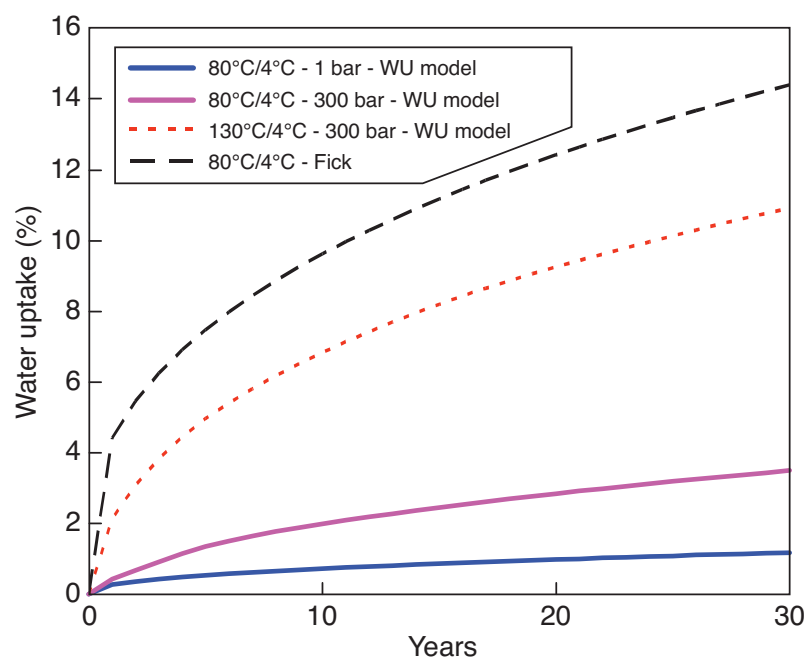

Figure 13

Global water uptake evolutions during ageing using different models.

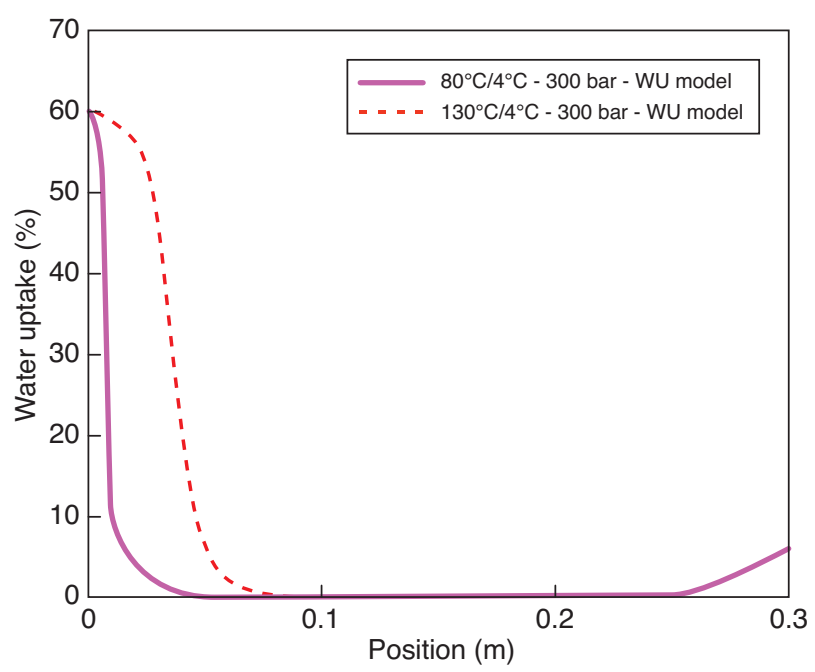

Figure 14

Water uptake simulated in a cross-section after 20 years of service using WU model - Hot surface at $80^{\circ} \mathrm{C}$ or $130^{\circ} \mathrm{C}$.

Another case was simulated with the hot face at $130^{\circ} \mathrm{C}$ to discuss the influence of the maximum temperature in the production pipe. Figure 13 presents the global water uptake evolution obtained with the WU model in various configurations, and the comparison with Fick's model. Figure 14 focuses on the water uptake profiles in a cross section simulated after 20 years of service, with limit conditions of $80^{\circ} \mathrm{C}$ or $130^{\circ} \mathrm{C}$ on the hot face.

It appears that the sacrificial thickness on the $130^{\circ} \mathrm{C}$ face is close to 10 centimeters. So there is a significant effect of the maximum temperature, which is also critical for the global water content. Consequences on the physical properties such as buoyancy and thermal conductivity will be discussed in the next paragraph.

\subsection{Consequences of Water Ingress on Some Physical properties}

\subsubsection{Consequences on buoyancy}

Since buoyancy is a global property which does not depend on water distribution in the material, computing buoyancy on large blocks does not present any difficulty on the basis of the global water uptake.

The evolution of density and the resulting percent buoyancy loss during ageing directly follow the global water uptake presented in Figure 13. Resulting percent buoyancy loss is plotted in Figure 15. As a result, it appears that the buoyancy loss after 20 years is limited to a few percent if the hot surface is at $80^{\circ} \mathrm{C}$. But it can be higher than $10 \%$ after 20 years if the hot surface is at $130^{\circ} \mathrm{C}$. Again, the prediction using the Fickian water uptake model is more pessimistic than the estimation resulting from the WU model: the buoyancy loss reaches $17 \%$ after 20 years, i.e. 4 times higher than predicted by the WU model in the same conditions.

\subsubsection{Consequences for Thermal Conductivity}

The thermal conductivity of aged syntactic foams obeys a simple mixture law (cf. Sect. 2) which is a function of the water uptake. Nevertheless, experimental measurements have been performed on small specimens in which water concentration were likely to be approximately homogeneous. Results are obviously not the same in a large block of foam in which absorbed water is mostly localized near the surfaces, the core remaining dry. In this paper, thermal conductivity computation was performed on the basis of the global water uptake assuming that a simple mixture law was respected. But it would also be interesting to compute the thermal conductivity in the cross-section as a function of the local water uptake of each element of the mesh.

From Figure 13, and considering $0.162 \mathrm{~W} \cdot \mathrm{m}^{-1} \cdot \mathrm{K}^{-1}$ as the initial thermal conductivity of the foam, computed thermal conductivity after 20 years of aging are:

- WU model - 1 bar and hot face at $80^{\circ} \mathrm{C}: 0.166 \mathrm{~W} \cdot \mathrm{m}^{-1} \cdot \mathrm{K}^{-1}$;

- WU model - 300 bar and hot face at $80^{\circ} \mathrm{C}: 0.175 \mathrm{~W} \cdot \mathrm{m}^{-1} \cdot \mathrm{K}^{-1}$;

- WU model - 300 bar and hot face at $130^{\circ} \mathrm{C}: 0.203 \mathrm{~W}$. $\mathrm{m}^{-1} \cdot \mathrm{K}^{-1}$

- Fickian model: $0.218 \mathrm{~W} \cdot \mathrm{m}^{-1} \cdot \mathrm{K}^{-1}$.

We notice that the apparent thermal conductivity evolution after 20 years is small $\left(<0.02 \mathrm{~W} . \mathrm{m}^{-1} \cdot \mathrm{K}^{-1}\right)$ if the hot surface is maintained at $80^{\circ} \mathrm{C}$. But the evolution is no longer negligible at a higher temperature. As mentioned previously, it would be interesting as a next step to compute directly thermal conductivity evolution in the cross-section 


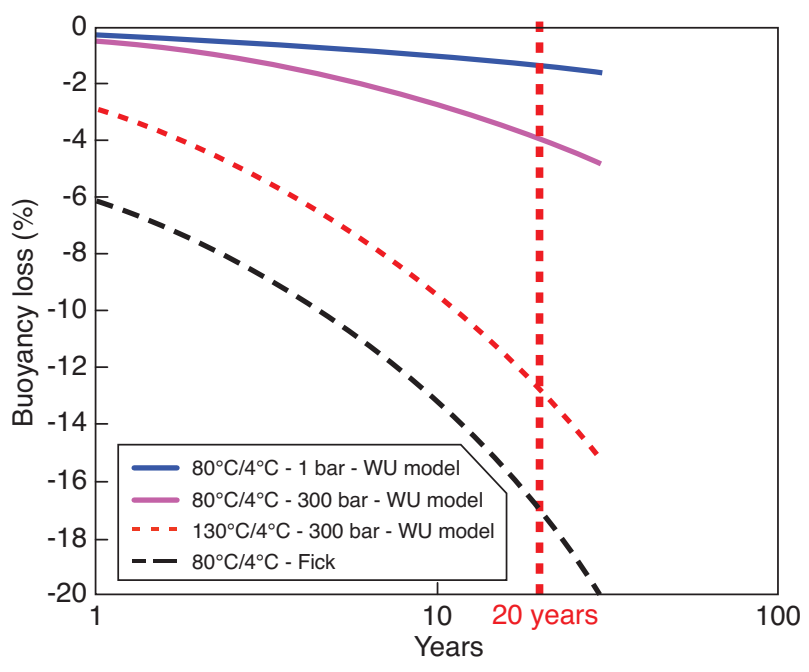

Figure 15

Percent buoyancy losses during ageing modelled for several water uptake models and conditions.

and resulting $U$ value as a function of the local water uptake in each element of the mesh.

\subsection{Conclusions on Water Uptake Modelling in a Representative Volume}

The simulation of water ingress profiles of a syntactic foam block under given aging conditions is an application example of the WU model. The model can easily be applied to other syntactic foam materials, other industrial configurations (pipe coating or more complex geometries such as dog house for singular points), and with different boundary conditions, etc.

The water uptake modelling provides computed physical property evolutions for design. Indeed, buoyancy and thermal properties shall remain compliant with the industrial application in service conditions (up to $130^{\circ} \mathrm{C}$ and $300 \mathrm{bar}$ ), provided that a sacrificial thickness is properly anticipated during the design. The sacrificial thickness to be taken into account using the traditional Fick law is two times greater than the one estimated by the WU model. This result could directly impact the design of future insulation structures.

For the time being, physical property evolution computed from the WU model are based on the global water uptake values using mixture laws. This is pertinent for buoyancy but not obvious for thermal conductivity since there is a water concentration gradient in the material. Additional model improvement could address this issue to deliver the evolution of the $\mathrm{U}$ value with respect to time.

\section{CONCLUSION}

The water uptake model outlined in this paper was developed to compute water intake and water ingress in syntactic foams during ageing under various ageing conditions: from $4^{\circ} \mathrm{C}$ to $130^{\circ} \mathrm{C}$ and from 1 bar to 300 bar. This physical model is based on 3 hydratation mechanisms, each mechanism being linked to a part of the syntactic foam microstructure:

- matrix hydration;

- glass hydration: matrix/microsphere interface filling and glass hydration/corrosion;

- microsphere cavity filling with water.

In comparison with experimental results, this WU model simulates water uptake curves with a satisfactory agreement for all geometries studied here and for three selected syntactic foams. Each specific behaviour is well reproduced whatever the ageing conditions and specimen size under study. Concerning the temperature dependence of the kinetics coefficients of the model, they follow Arrhenius laws with good correlation coefficients, which confirms the relevance of the WU model.

The WU model has then been used to compute water ingress and water uptake in a large block of foam immersed in water (to approximate a half shell structure). Simulation results show that a sacrificial thickness has to be designed to keep a foam block with both acceptable buoyancy and thermal conductivity properties after 20 years. The size of the sacrificial thickness estimated by the WU model is of course dependent on both temperature and pressure during aging, but it is notably two times lower than the sacrificial thickness estimated by the traditional Fick law. This result could directly impact the design of future insulation structures.

Further work should introduce the mechanical resistance of microspheres in the water uptake model to account for the effects of the hydrostatic pressure [15] and glass corrosion [16].

\section{ACKNOWLEDGMENTS}

The authors wish to greatly acknowledge the sponsors of the Joint Industry Project TIDEEP (Thermal Insulation of Deepsea flowlines) for their financial support and their permission to publish the paper.

\section{REFERENCES}

1 John A., McFarlane G. (2007) Global deepwater expenditure to exceed \$118 billion through 2012, Offshore Magazine, 70-73.

2 Bouchonneau N., Sauvant-Moynot V., Grosjean F., Choqueuse D., Poncet E., Perreux D. (2007) Thermal insulation material for subsea pipelines: benefits of instrumented full scale testing to predict the long term thermo-mechanical behaviour, OTC 2007, paper No. 18679 , Houston, Texas, USA. 
3 3M, Scotchlite Glass Bubbles, technical data from manufacturer.

4 Emerson \& Cuming, Eccosphereres Glass Microspheres, technical data from manufacturer.

5 Maire E., Gimenez N., Sauvant-Moynot V., Sautereau H. (2006) $\mathrm{X}$-ray tomography and 3D image analysis of epoxy-glass syntactic foams, Philos. T. Roy. Soc. A 364, 69-88.

6 Adrien J., Maire E., Gimenez N., Sauvant-Moynot V. (2007) Experimental study of syntactic foams using Xray tomography, Acta Mater. 55, 1667-1679

7 Choqueuse D., Chomard A., Chauchot P. (2004) How to provide relevant data for the prediction of long term behavior of insulation materials under hot/wet conditions? OTC 2004, paper No. 16503, Houston, Texas, USA.

8 Choqueuse D., Chomard A., Bucherie C. (2002) Insulation material for ultradeepsea flow assurance: evaluation of material properties, OTC 2002, paper No. 14115, Houston, Texas, USA.

9 Fick A. (1855) Ann. Phys. Lpz. 170, 59.

10 Crank J. (1956) The mathematics of diffusion, Clarendon Press, Oxford.

11 Crank J., Park G.S. (1986) Diffusion in polymers, Academic Press, London .

12 Gimenez N. (2005) Vieillissement hydrolytique de mousses syntactiques époxyde-amine/verre pour l'isolation thermique sous hautes pressions : mécanismes de dégradation et simulation de la prise en eau, PhD Thesis, INSA Lyon, France.
13 Sauvant-Moynot V., Gimenez N., Sautereau H. (2006) Novel syntactic foams for thermal insulation in deep water: degradation mechanisms and modeling of hygrothermal aging, J. Mater. Sci. 41, 13, 4047-4064.

14 Gimenez N., Sauvant-Moynot V., Sautereau H. (2005) Wet ageing of syntactic foams under high pressure / high temperature in deionized water, OMAE 2005, paper 67449, Halkidiki, Greece.

15 Choqueuse D., Perreux D., Sauvant-Moynot V. (submitted) Modeling approach for damageable mechanical behavior of glass/polymer syntactic foams under hydrostatic pressure, $J$. Mater. Sci.

16 Brini A., Pradel F., Benhamida A., Dumontet H. (2003) Ageing damage of immersed syntactic foams under coupled effects of pressure and aqueous corrosion, ICCM-14, San Diego California, USA.

17 Adrien J., Maire E., Gimenez N., Sauvant-Moynot V. (2007) Experimental study of the compression behaviour of syntactic foams by in situ X-ray tomography, Acta Mater. 55, 1667-1679.

Final manuscript received in May 2008 Published online in February 2009 or distributed for profit or commercial advantage and that copies bear this notice and the full citation on the first page. Copyrights for components of this work owned by others than IFP must be honored. Abstracting with credit is permitted. To copy otherwise, to republish, to post on servers, or to redistribute to lists, requires prior specific permission and/or a fee: Request permission from Documentation, Institut français du pétrole, fax. +33147527078 , or revueogst@ifp.fr. 